\title{
Saúde da população em situação de rua e suas vulnerabilidades em saúde: reflexões sobre o processo saúde-doença
}

\author{
Lauro José Franco Melo ${ }^{a}$, Francisca Bruna Arruda Aragão ${ }^{b^{*}}$, Tânia Silva Gomes \\ Carneiro $^{\mathrm{a}}$, Regina Célia Fiorati ${ }^{\mathrm{a}}$
}

${ }^{a}$ Faculdade de Medicina de Ribeirão Preto, Universidade de São Paulo-USP, Ribeirão Preto, SP, Brasil

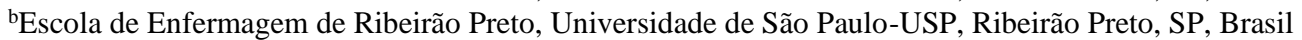

\begin{abstract}
Histórico do Artigo
Recebido em:

03/07/2019

Aceito em:

$29 / 05 / 2020$

Palavras-chave:

Pessoas em situação

de rua;

vulnerabilidade em

saúde; Atenção

Primária à Saúde.
\end{abstract}

\begin{abstract}
RESUMO
O direito a uma vida digna para todos requer a superação de desafios impostos aos grupos mais vulneráveis, que são socialmente exclusos de garantia universal, como a acesso à saúde. Primária à Saúde O estudo objetiva analisar os processos saúde-doença e suas principais vulnerabilidades em saúde das pessoas em situação de rua que procuram os serviços de Atenção Primária a Saúde. Realizou-se uma revisão integrativa de literatura, utilizando-se os seguintes termos de busca: População em Situação de Rua; Processo saúde doença; vulnerabilidade em saúde. Foram analisados 07 estudos resultantes do levantamento bibliográfico em três bases de dados - (U. S. National Library of Medicine), SciELO (Scientific Eletronic Library Online), e Lilacs (Literatura Latino-Americana e do Caribe em Ciências da Saúde). Os resultados mostram que as principais barreiras identificadas foram a insegurança e as prioridades concorrentes. Conclui-se que este estudo contribuiu para a conhecimento específico da população em situação de rua, suscitando a discussão e fornecendo subsídios para capacitação de recursos humanos e para práticas assistenciais de saúde.
\end{abstract}

Health of the street population and its health vulnerabilities: reflections on the healthdisease process

\section{ABSTRACT}

The right to a decent life for all requires overcoming challenges imposed on the most vulnerable groups, which are socially excluded from universal guarantee, such as access to health. Primary Health Care The study aims to analyze the health-disease processes and their main health vulnerabilities of street people seeking Primary Health Care services. An integrative literature review was carried out using the following search terms: Street Population; Health Illness Process; Health Vulnerability. We analyzed 07 studies resulting from the bibliographic survey in three databases - (U. S. National Library of Medicine), SciELO (Scientific Electronic Library Online), and Lilacs (Latin American and Caribbean Literature in Health Sciences). The results show that the main barriers identified were insecurity and competing priorities. It is concluded that this study contributed to the specific knowledge of the street population, stimulating discussion and providing subsidies for human resource training and health care practices.

\section{Introdução}

O fenômeno da população em situação de rua tem afetado diversos países em todo o mundo e é polissêmico e decorrente de um processo de múltiplas determinações: as crises econômicas, a precarização das relações e condições de trabalho e a debilidade dos sistemas de seguridade (1). Ghirardi et al. (2) afirmam que esta população sofre a marginalização provocada pelo capital, tornando-se socialmente inútil e, portanto, socialmente excluso, mesmo de direitos humanos básicos e de garantia universal, como o acesso à Saúde.

É fundamental frisar que a população em situação de rua apresenta aspectos heterogêneos quanto à identidade, origem geográfica, causalidade da situação de rua, caracterização sociodemográfica, tempo na rua, trajetórias, incidências de doenças e

\footnotetext{
*Autor correspondente: aragao_bruna@ hotmail.com (Aragão B.A.)
} 
deficiências (3).

Devido à complexidade e às dificuldades de generalizações e metodologias, o Brasil produziu conhecimento insuficiente sobre condições de vida das populações em situação de rua e de conquistas no âmbito das políticas públicas de assistência, saúde e inclusão desse grupo social (8). Da mesma forma, há uma escassez de estudos que avaliam as condições de saúde das pessoas em situação de rua (4).

As respostas institucionais à tal questão foram "assumidas" pela assistência social, por via assistencialista, e observa-se atualmente um processo de justificativa 'medicalizante' desse fenômeno (5), bem como um processo que objetiva retirar tal população das ruas a fim de transformar os espaços da cidade em locais atraentes para empreendimentos imobiliários e para circulação de pessoas de nível socioeconômico elevado como afirma (6).

O contraste entre as condições de vulnerabilidade desse grupo social e a insuficiência dos recursos obtidos através da rede de saúde, entretanto, é indicador de que a situação de saúde dos moradores de rua não mudou de maneira significativa nos últimos anos $(7,8)$. Os profissionais de saúde tem relatado experiências pontuais de sucesso, quadros epidemiológicos restritos a algumas unidades de saúde e centros de referência para álcool e drogas como bases para o desenvolvimento de políticas públicas de saúde para esta população (5).

Ainda que haja experiências exitosas, estas são pontuais e esbaram em dificuldades de utilização eficaz dos serviços de saúde pelas pessoas desse grupo social. Carneiro Junior (9) relata que as principais dificuldades devem-se a: concepção particular do adoecimento-cuidado, organização técnico-administrativa dos serviços - como exigência de documentação, restrição no atendimento da demanda espontânea, limites da atuação inter setorial -, bem como preconceitos de profissionais. Portanto, faz-se necessárias novas estratégias de cuidado e novos processos de trabalho proativos na atenção à saúde; bem como formas de atendimento e diagnóstico flexíveis que considerem inclusive a atenção extramuros ou em meio aberto estendendo o serviço de saúde à população em situação de rua (5).

Perante esse cenário de iniquidades, é evidente e urgente a necessidade de melhor entendermos o processo saúde-doença da população em situação de rua e suas especificidades, e conhecer seu acesso à saúde, especialmente, aos serviços da Atenção Primária à Saúde, começando a entender esse processo pelo município de Ribeirão Preto. O processo saúde-doença, em sua compreensão hegemônica, é definido pelo modelo multicausal que reduz a explicação do aparecimento das doenças aos fatores de risco. Essa relação considera os fatores biológicos com mesmo peso e importância que os sociais (10).

O objetivo do estudo é analisar os processos saúde-doença e suas principais vulnerabilidades em saúde das pessoas em situação de rua que procuram os serviços de Atenção Primária à Saúde. Assim, busca-se contribuir para o conhecimento específico da população em situação de rua, suscitando a discussão e fornecendo subsídios para capacitação de recursos humanos e para práticas assistenciais de saúde.

Com o conhecimento produzido neste trabalho, poderá sensibilizar gestores de saúde, entre outros, para a construção de políticas intersetoriais de promoção, prevenção e recuperação de saúde e de enfrentamento às iniquidades sociais que esses indivíduos estão sujeitos por viverem nessa situação de vida, bem como para identificar possíveis fatores que prejudicam o acesso dessas pessoas aos serviços de Atenção Primária à Saúde. Desta forma, poderão ser desenvolvidas possíveis ações para saná-los no intuito de contribuir para a integralidade de saúde das pessoas em situação de rua. 


\section{Materiais e Métodos}

Foi realizada uma revisão bibliográfica, aplicando-se a análise integrativa sobre à saúde das pessoas que vivenciam situação de rua. Para o desenvolvimento do estudo, as seis etapas que compõem a elaboração de uma revisão integrativa foram percorridas: 1) estabelecimento da questão de pesquisa; 2) busca na literatura; 3) categorização dos estudos; 4) avaliação dos estudos incluídos; 5) interpretação dos resultados; e 6) síntese do conhecimento (11). A questão norteadora desta pesquisa foi: "Quais são os dados abordados pela literatura científica nacional e internacional no que diz respeito aos processos saúde-doença e suas principais vulnerabilidades em saúde das pessoas que vivem em situação de rua que procuram os serviços de Atenção Primária à Saúde?" Para responder a esse questionamento, realizou-se um levantamento bibliográfico em três bases de dados - PubMed (U. S. National Library of Medicine), SciELO (Scientific Eletronic Library Online), e Lilacs (Literatura Latino-Americana e do Caribe em Ciências da Saúde), tendo sido selecionadas as seguintes palavras-chaves: População em Situação de Rua; Processo saúde doença; vulnerabilidade em saúde. A coleta de dados ocorreu no mês de fevereiro de 2018.

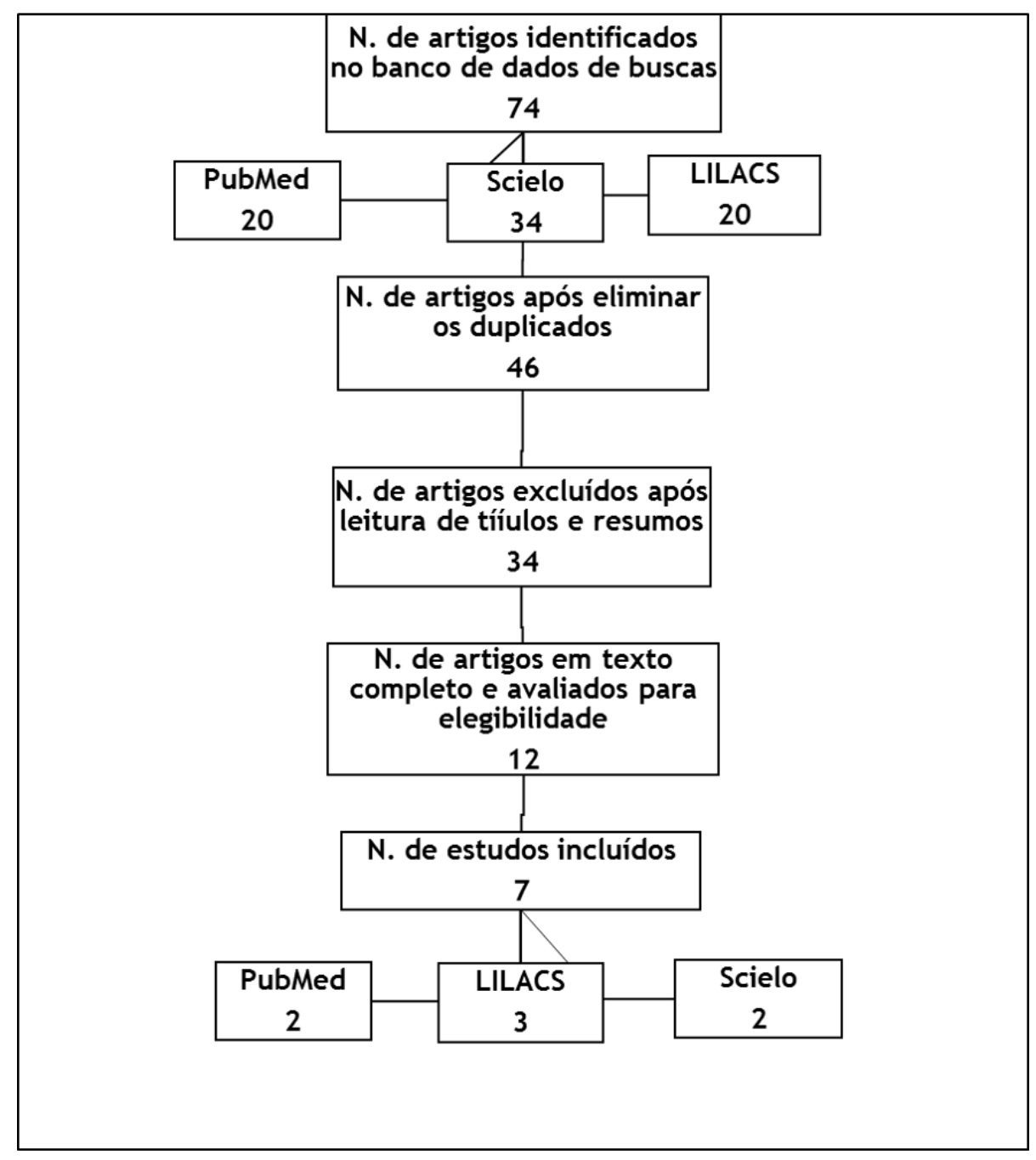

Figura 1 - Fluxograma com o processo de seleção dos artigos para a revisão, Ribeirão Preto, 2017. 
Os critérios utilizados para a seleção dos artigos foram: artigos científicos disponíveis na íntegra na internet, utilizando o Virtual Private Network (VPN) da Universidade de São Paulo - USP, escritos na língua portuguesa ou em inglês, publicados entre 2006 e 2018, o que pode ser justificado pelo fato de terem sido utilizadas referências-base, relativos a artigos mais antigos. Foram excluídos os artigos relacionados à criança, ao adolescente e ao idoso (em função de suas especificidades), os trabalhos repetidos e os que não atendiam aos propósitos desta pesquisa. Inicialmente, os estudos identificados utilizando os três descritores foram selecionados por meio da leitura do título. Nessa etapa, foram selecionados somente os artigos que abordavam a temática deste estudo e os que foram publicados no período definido; e foram excluídos os artigos repetidos.

Posteriormente, procedeu-se à leitura dos resumos dos trabalhos, excluindo-se os que não estavam integralmente disponíveis na internet e os que abordavam crianças, adolescentes e idosos. Desse modo, 7 artigos científicos foram analisados neste estudo. O fluxograma apresentado esquematiza o percurso do levantamento bibliográfico adotado pelos pesquisadores para a elaboração desta pesquisa (Figura 1).

Para análise do material bibliográfico, o pesquisador realizou a leitura dos artigos na íntegra e, a partir desse momento, foi elaborado um formulário que contemplava informações referentes título e referência, base de dados pesquisada, a população do estudo, o tipo de estudo, os objetivos dos estudos e, por fim, os resultados relevantes apresentados (Quadro 1).

Após a seleção, efetuou-se o processo de análise dos artigos com base na extração e análise dos dados (12) sobre os aspectos relacionados à saúde das pessoas que vivem em situação de rua.

\section{Resultados}

Foram analisados 7 artigos científicos publicados em periódicos nacionais e internacionais e que tinham relação com a saúde de pessoas que vivenciam situação de rua, conforme Quadro 1.

Quadro 1 - Formulário construído a partir dos artigos selecionados para a revisão integrativa. Ribeirão Preto, 2017.

\begin{tabular}{|c|c|c|c|c|c|}
\hline Autor/ano & $\begin{array}{l}\text { Base de } \\
\text { dados }\end{array}$ & $\begin{array}{c}\text { População/ } \\
\text { amostra }\end{array}$ & $\begin{array}{l}\text { Tipo de } \\
\text { estudo }\end{array}$ & $\begin{array}{l}\text { Objetivos do } \\
\text { estudo }\end{array}$ & $\begin{array}{c}\text { Resultados } \\
\text { apresentados pelos } \\
\text { artigos revisados }\end{array}$ \\
\hline $\begin{array}{l}\text { Aguiar; } \\
\text { Iriart(13) } \\
(2012)\end{array}$ & LILACS & $\begin{array}{l}13 \text { indivíduos } \\
\text { em situação de } \\
\text { rua }\end{array}$ & $\begin{array}{l}\text { Estudo } \\
\text { qualitativo de } \\
\text { enfoque } \\
\text { antropológico } \\
\text { ' com } \\
\text { observação } \\
\text { participante e } \\
\text { entrevistas } \\
\text { semiestrutura } \\
\text { das }\end{array}$ & $\begin{array}{l}\text { Analisar } \\
\text { práticas e } \\
\text { significados } \\
\text { atribuídos à } \\
\text { saúde e à } \\
\text { doença pela } \\
\text { população em } \\
\text { situação de rua } \\
\text { em Salvador, } \\
\text { Bahia, Brasil. }\end{array}$ & $\begin{array}{l}\text { As condições de } \\
\text { vida e saúde deste } \\
\text { grupo são muito } \\
\text { precárias, sendo a } \\
\text { violência } \\
\text { sobressalente nas } \\
\text { narrativas. } \\
\text { principais } \\
\text { problemas de saúde } \\
\text { foram o abuso de } \\
\text { substâncias } \\
\text { psicoativas, } \\
\text { HIV/AIDS, } \\
\text { transtornos mentais, } \\
\text { problemas } \\
\text { odontológicos, } \\
\text { dermatológicos e } \\
\text { gastrointestinais. A } \\
\text { saúde foi associada, }\end{array}$ \\
\hline
\end{tabular}




\begin{tabular}{|c|c|c|c|c|c|}
\hline Autor/ano & $\begin{array}{c}\text { Base de } \\
\text { dados }\end{array}$ & $\begin{array}{c}\text { População/ } \\
\text { amostra }\end{array}$ & $\begin{array}{l}\text { Tipo de } \\
\text { estudo }\end{array}$ & $\begin{array}{l}\text { Objetivos do } \\
\text { estudo }\end{array}$ & $\begin{array}{c}\text { Resultados } \\
\text { apresentados pelos } \\
\text { artigos revisados }\end{array}$ \\
\hline & & & & & $\begin{array}{l}\text { entre outros } \\
\text { significados, à } \\
\text { capacidade de } \\
\text { resistir ao cotidiano } \\
\text { de dificuldades, } \\
\text { enquanto a doença } \\
\text { vinculou-se ao } \\
\text { estado de debilidade } \\
\text { impeditivo de lutar } \\
\text { pela sobrevivência. } \\
\text { Os serviços de saúde } \\
\text { são procurados em } \\
\text { situações graves e } \\
\text { urgentes. Conclui-se } \\
\text { que há necessidade } \\
\text { de políticas } \\
\text { específicas, visando } \\
\text { garantir condições } \\
\text { de vida adequadas e } \\
\text { acesso à saúde para } \\
\text { esta população. }\end{array}$ \\
\hline $\begin{array}{l}\text { Ferreira et al. } \\
\text { (3) (2016) }\end{array}$ & LILACS & $\begin{array}{l}18 \text { pessoas em } \\
\text { situação de rua, } \\
\text { entre } 20 \text { e } 40 \\
\text { anos. }\end{array}$ & $\begin{array}{l}\text { Estudo } \\
\text { qualitativo, } \\
\text { com coleta } \\
\text { através de } \\
\text { entrevista } \\
\text { semiestrutura } \\
\text { da e dados } \\
\text { analisados } \\
\text { por técnica de } \\
\text { análise de } \\
\text { conteúdo. }\end{array}$ & 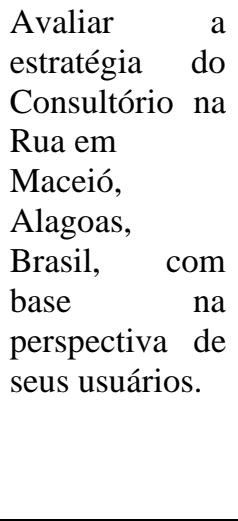 & $\begin{array}{lr}\text { Os resultados } \\
\text { demonstraram que a } \\
\text { estratégia é avaliada } \\
\text { positivamente } \\
\text { e que se constitui } \\
\text { como suporte social } \\
\text { não apenas em } \\
\text { questões } \\
\text { relativas à saúde- } \\
\text { doença, } \\
\text { também } \\
\begin{array}{l}\text { aspectos da vida } \\
\text { cotidiana. }\end{array}\end{array}$ \\
\hline $\begin{array}{l}\text { Silva et al. } \\
(14)(2015)\end{array}$ & LILACS & $\begin{array}{l}6 \text { profissionais } \\
\text { de saúde, } 8 \\
\text { profissionais } \\
\text { da educação } \\
\text { permanente e } \\
\text { um informante- } \\
\text { chave } \\
\text { representante } \\
\text { do movimento } \\
\text { social }\end{array}$ & $\begin{array}{l}\text { Estudo de } \\
\text { caso, tendo } \\
\text { por } \\
\text { procedimento } \\
\text { s } \\
\text { metodológico } \\
\text { s: observação } \\
\text { direta, } \\
\text { entrevistas } \\
\text { semiestrutura } \\
\text { das e análise } \\
\text { documental. }\end{array}$ & $\begin{array}{l}\text { Compreender } \\
\text { as práticas de } \\
\text { cuidado de um } \\
\text { Consultório na } \\
\text { Rua, em } \\
\text { Manguinhos/R } \\
\mathrm{J} \text {, de forma a } \\
\text { contribuir com } \\
\text { o debate da } \\
\text { Atenção a } \\
\text { Primária à } \\
\text { Saúde para } \\
\text { populações } \\
\text { específicas. }\end{array}$ & 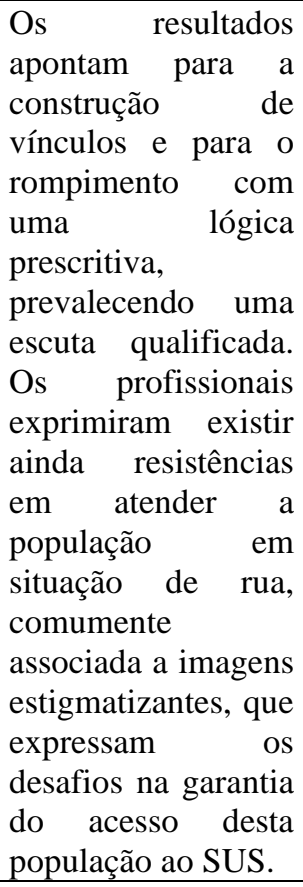 \\
\hline Carneiro & Scielo & & Relato & Relatar & As dificuldades de \\
\hline
\end{tabular}




\begin{tabular}{|c|c|c|c|c|c|}
\hline Autor/ano & $\begin{array}{l}\text { Base de } \\
\text { dados }\end{array}$ & $\begin{array}{c}\text { População/ } \\
\text { amostra }\end{array}$ & $\begin{array}{l}\text { Tipo de } \\
\text { estudo }\end{array}$ & $\begin{array}{l}\text { Objetivos do } \\
\text { estudo }\end{array}$ & $\begin{array}{c}\text { Resultados } \\
\text { apresentados pelos } \\
\text { artigos revisados }\end{array}$ \\
\hline $\begin{array}{l}\text { Junior et al. } \\
\text { (9) (2010) }\end{array}$ & & & experiência & $\begin{array}{l}\text { experiência na } \\
\text { implantação da } \\
\text { atenção à saúde } \\
\text { da população } \\
\text { em situação de } \\
\text { rua da cidade } \\
\text { de São Paulo, } \\
\text { visando à } \\
\text { equidade de } \\
\text { acesso às ações } \\
\text { de saúde no } \\
\text { Sistema Único } \\
\text { de Saúde. }\end{array}$ & $\begin{array}{l}\text { utilização } r \text { dos } \\
\text { serviços de saúde } \\
\text { por esses indivíduos } \\
\text { devem-se do } \\
\text { concepção } \\
\text { adoecimento- } \\
\text { cuidado, } \\
\text { organização } \\
\text { técnico- } \\
\text { administrativa dos } \\
\text { serviços, } \\
\text { preconceitos } \\
\text { profissionais } \\
\text { usuários } \\
\text { e fragilidades de } \\
\text { ações inter setoriais, } \\
\text { entre outros. } \\
\text { São necessários } \\
\text { novos processos de } \\
\text { trabalho pró-ativos } \\
\text { na atenção à saúde } \\
\text { que incorporem } \\
\text { particularidades } \\
\text { desses indivíduos, } \\
\text { garantindo, assim, o } \\
\text { acesso. Nesse } \\
\text { sentido, a Estratégia } \\
\text { Saúde da Família, } \\
\text { por suas } \\
\text { características, } \\
\text { responde a tais } \\
\text { necessidades. }\end{array}$ \\
\hline $\begin{array}{l}\text { Barata et al. } \\
(15)(2015)\end{array}$ & Scielo & $\begin{array}{l}251 \text { indivíduos } \\
\text { em situação de } \\
\text { rua que se } \\
\text { autodenominar } \\
\text { am transexuais } \\
\text { na cidade de } \\
\text { São Paulo }\end{array}$ & $\begin{array}{l}\text { Estudo } \\
\text { quantitativo } \\
\text { através de } \\
\text { aplicação de } \\
\text { questionário } \\
\text { estruturado } \\
\text { contendo } \\
\text { dados } \\
\text { sociodemogr } \\
\text { áficos, } \\
\text { suporte } \\
\text { social, estado } \\
\text { de saúde, } \\
\text { consumo de } \\
\text { álcool, tabaco } \\
\text { ou drogas, } \\
\text { violência e } \\
\text { acesso a } \\
\text { serviços de } \\
\text { saúde }\end{array}$ & $\begin{array}{l}\text { Descrever as } \\
\text { características } \\
\text { sociodemográfi } \\
\text { cas, o } \\
\text { estado de saúde } \\
\text { e o acesso a } \\
\text { serviços na } \\
\text { população em } \\
\text { situação de rua } \\
\text { em uma } \\
\text { amostra em três } \\
\text { albergues do } \\
\text { centro da } \\
\text { cidade de São } \\
\text { Paulo. }\end{array}$ & $\begin{array}{l}\text { O perfil } \\
\text { sociodemográfico } \\
\text { dos indivíduos } \\
\text { pesquisados é } \\
\text { semelhante ao do } \\
\text { último censo da } \\
\text { população em } \\
\text { situação de rua na } \\
\text { cidade de São Paulo. } \\
\text { Pequena parcela dos } \\
\text { entrevistados } \\
\text { apresentou motivos } \\
\text { circunstanciais para } \\
\text { estarem albergados, } \\
\text { tais como } \\
\text { tratamento de saúde } \\
\text { na capital ou } \\
\text { trabalhos } \\
\text { temporários. } \\
\text { maioria atribuiu sua } \\
\text { condição a a } \\
\text { problemas de ordem } \\
\text { econômica ou } \\
\text { afastamento/ } \\
\text { ausência de relações }\end{array}$ \\
\hline
\end{tabular}




\begin{tabular}{|c|c|c|c|c|c|}
\hline Autor/ano & $\begin{array}{c}\text { Base de } \\
\text { dados }\end{array}$ & $\begin{array}{l}\text { População/ } \\
\text { amostra }\end{array}$ & $\begin{array}{l}\text { Tipo de } \\
\text { estudo }\end{array}$ & $\begin{array}{l}\text { Objetivos do } \\
\text { estudo }\end{array}$ & $\begin{array}{c}\text { Resultados } \\
\text { apresentados pelos } \\
\text { artigos revisados }\end{array}$ \\
\hline & & & & & $\begin{array}{l}\text { familiares } \\
\text { motivados por } \\
\text { desavenças, } \\
\text { desemprego e uso de } \\
\text { álcool ou drogas. } \\
\text { Expressiva parcela } \\
\text { do grupo em } \\
\text { situação de rua } \\
(55 \%) \text { considerou } \\
\text { sua saúde regular, } \\
\text { ruim ou muito ruim, } \\
\text { refletindo as } \\
\text { precárias condições } \\
\text { de vida. } \\
\text { Aproximadamen-te } \\
40 \% \text { dos indivíduos } \\
\text { que referiram ter } \\
\text { tido um problema de } \\
\text { saúde na não } \\
\text { procuraram } \\
\text { atendimento, entre } \\
\text { aqueles em situação } \\
\text { de rua. } \\
\text { As taxas de } \\
\text { internação no último } \\
\text { ano também foram } \\
\text { altas para uma } \\
\text { população composta } \\
\text { fundamentalmente } \\
\text { por adultos de } 40 \text { a } \\
59 \text { anos, refletindo, } \\
\text { mais uma vez, as } \\
\text { necessidades de } \\
\text { saúde intimamente } \\
\text { relacionadas com as } \\
\text { precárias condições } \\
\text { de vida desse grupo } \\
\text { populacional. }\end{array}$ \\
\hline $\begin{array}{l}\text { Wright; } \\
\text { Tompkins } \\
\text { (16) (2006) }\end{array}$ & PubMed & $\begin{array}{l}\text { Database do } \\
\text { Medline, } \\
\text { EMBASE, } \\
\text { PsycINFO, } \\
\text { CINAHL, Web } \\
\text { of Science e } \\
\text { biblioteca } \\
\text { Cochrane }\end{array}$ & $\begin{array}{l}\text { Revisão e } \\
\text { síntese das } \\
\text { evidencias } \\
\text { atuais }\end{array}$ & $\begin{array}{l}\text { Examinar } \\
\text { criticamente a } \\
\text { literatura } \\
\text { internacional } \\
\text { pertinente à } \\
\text { atenção à saúde } \\
\text { de pessoas em } \\
\text { situação de rua } \\
\text { e discutir a } \\
\text { efetividade de } \\
\text { intervenções } \\
\text { terapêuticas. }\end{array}$ & $\begin{array}{lr}\text { A } & \text { revisão } \\
\text { identificou } & \text { que, } \\
\text { como a morbidade } \\
\text { múltipla é comum } \\
\text { entre a população } \\
\text { em situação de rua, a } \\
\text { atenção primária em } \\
\text { saúde acessível e } \\
\text { disponível é pré- } \\
\text { requisito } \\
\text { intervenções em } \\
\text { saúde efetivas. }\end{array}$ \\
\hline $\begin{array}{l}\text { White; } \\
\text { Newman(17) } \\
(2015)\end{array}$ & PubMed & $\begin{array}{ll}\text { Dadabase } & \text { do } \\
\text { PubMed, } & \\
\text { CINAHL } & \text { e } \\
\text { PsycINFO } & \end{array}$ & $\begin{array}{l}\text { Revisão } \\
\text { quase- } \\
\text { sistemática } \\
\text { de literatura }\end{array}$ & $\begin{array}{l}\text { Identificar } \\
\text { barreiras e } \\
\text { facilitadores à } \\
\text { atenção } \\
\text { primária em } \\
\text { saúde entre a } \\
\text { população em }\end{array}$ & $\begin{array}{l}\text { A revisão } \\
\text { identificou } \\
\text { múltiplas barreiras } \\
\text { ao acesso primário } \\
\text { pelos moradores de } \\
\text { rua: falta de seguro e } \\
\text { prioridades }\end{array}$ \\
\hline
\end{tabular}




\begin{tabular}{|c|c|c|c|c|c|}
\hline Autor/ano & $\begin{array}{c}\text { Base de } \\
\text { dados }\end{array}$ & $\begin{array}{c}\text { População/ } \\
\text { amostra }\end{array}$ & $\begin{array}{l}\text { Tipo de } \\
\text { estudo }\end{array}$ & $\begin{array}{c}\text { Objetivos do } \\
\text { estudo }\end{array}$ & $\begin{array}{c}\text { Resultados } \\
\text { apresentados pelos } \\
\text { artigos revisados }\end{array}$ \\
\hline & & & & $\begin{array}{l}\text { situação de rua } \\
\text { e prover } \\
\text { recomendação } \\
\text { para médicos e } \\
\text { profissionais } \\
\text { de saúde para } \\
\text { aprimorar a } \\
\text { saúde entre esta } \\
\text { população. }\end{array}$ & $\begin{array}{l}\text { concorrentes. Os } \\
\text { facilitadores } \\
\text { incluem: os sistemas } \\
\text { de prestação de } \\
\text { cuidados de saúde } \\
\text { adaptados e com } \\
\text { uma fonte regular de } \\
\text { cuidados. }\end{array}$ \\
\hline
\end{tabular}

\section{Discussão}

É fundamental destacar a conceituação de população em situação de rua, caracterizada como grupo heterogêneo comum em diversos aspectos, como a pobreza extrema, vínculos familiares fragilizados ou rompidos e inexistência de moradia convencional (18).

A revisão de bibliografia realizada pelo pesquisador reafirmou que em nosso país, há escassos dados epidemiológicos disponíveis acerca da população em situação de rua; e que os existentes se concentram na sua caracterização demográfica (19). No que tange à saúde das pessoas que vivem na rua, os estudos obtiveram aumento no decorrer dos anos, porém encontram-se concentrados especificamente no perfil epidemiológico de doenças (20) e na incidência de transtornos mentais dessa população.

Um número reduzido de estudos encontrados propuseram-se a descrever e analisar uma prática ou práticas de um órgão específico, com objetivo de dar visibilidade à experiência de atenção às pessoas que moram nas ruas, a exemplo de Santos (21): apresentação e discussão de práticas biopolíticas de atendimento às pessoas em situação de rua desenvolvidas na Casa Abrigo para Moradores de Rua - CAMARII, vinculada a Fundação João Paulo XXII, órgão de gestão da Assistência Social do Município de Belém, no estado do Pará. Desse modo, não foram encontrados estudos com objetivo de entender a rede de atenção à saúde, tampouco entender como se dá o acesso à Atenção Primaria pelos moradores de rua.

Quanto ao acesso das pessoas em situação de rua aos serviços de saúde, este se dá por meio da Atenção Primária à Saúde (APS), porém o mesmo tem apresentado muitos obstáculos, tais como a falta de compreensão da constitucionalidade da atenção em saúde e a exigência acerca da documentação necessária para o atendimento nos serviços, preconceitos de alguns profissionais, entre outros. Assim, foi criado o consultório na rua, a fim de minimizar tais barreiras $(22,23)$. Por outro lado, nos estudos de White e Newman (17), dentre as barreiras identificadas nesse processo, pelos moradores de rua, a insegurança e as prioridades concorrentes (dificuldade em encontrar comida, abrigo, roupas, um lugar para lavar e/ou um lugar para usar o banheiro). Dentre os facilitadores, tem-se os sistemas de prestação de cuidados de saúde adaptados e apresentando uma fonte regular de cuidados.

Esta pesquisa se apresenta como de grande relevância, ao aprofundar o entendimento acerca das dificuldades e possibilidades no que diz respeito aos programas e políticas públicas geradoras de equidade na atenção à saúde das pessoas em situação de rua, analisando as necessidades de saúde da população em situação de rua, através de seu próprio entendimento sobre adoecimento. Assim sendo, buscou-se contribuir para a construção de políticas públicas inter setoriais de promoção, prevenção e recuperação de saúde e de enfrentamento às iniquidades sociais, para a desnaturalização da desigualdade e para a sensibilização social voltada às pessoas em situação de rua. 


\section{Conclusão}

A análise da produção científica brasileira sobre as pessoas que fazem da rua a sua moradia tendo a saúde como objeto de análise aponta que muito ainda há de ser feito, como a aplicação das políticas de forma adequada, para garantir o atendimento das demandas e principais necessidades de saúde das pessoas que vivenciam situação de rua. Frente à situação apresentada, e reconhecendo a complexidade de se prestar assistência de qualidade às pessoas que vivenciam situação de rua, deve ser reforçada a inclusão do tema na formação acadêmica de graduandos da área da saúde, para que conheçam e, futuramente, incorporem esse aprendizado às suas práticas profissionais por meio do ensino, pesquisa, extensão e educação profissional permanente.

Deve-se investir na formação de pessoas críticas, capazes de atuar no atendimento de forma comprometida com as particularidades dos modos de vida e das necessidades de saúde das pessoas em situação de rua e, dessa forma, assegurar a equidade e atenção integral à saúde desse grupo específico. Acredita-se na relevância do presente estudo, pois permitiu visualizar a preocupação da comunidade científica com a temática, evidenciada pelo aumento do número de trabalhos que vêm sendo desenvolvidos ao longo da última década.

As pesquisas mostraram-se conectadas aos avanços sociais e políticos ao refletirem sobre a importância das políticas públicas específicas construídas para as pessoas que vivenciam a situação de rua, as quais asseguraram, no âmbito legal, um conjunto de direitos sociais, ampliando as condições de acesso aos serviços de saúde. Ao mesmo tempo, discutem os desafios de garantir a atenção integral à saúde e de construir estratégias efetivas de cuidado à saúde considerando necessidades, demandas e dignidade dessa população.

6. Conflito de interesses: os autores declaram não haver conflito de interesses.

\section{Referências}

1. Fiorati RC, Xavier JJS, Lobato BC, et al. Iniquidade e exclusão social: estudo com pessoas em situação de rua em Ribeirão Preto/SP. Revista Eletrônica Gestão \& Saúde 2015; 6(3): 2120-2135.

2. Ghirardi MIG, et al. Vida na rua e cooperativismo: transitando pela produção de valores. Interface: Comunicação, Saúde, Educação 2005; 9(18): 601-610.

3. Ferreira CPS, Rozendo CA, Melo GB. Consultório na rua em uma capital do Nordeste brasileiro: o olhar de pessoas em situação de vulnerabilidade social. Cad. Saúde Pública 2016; 32(8):1-10.

4. Paiva IKS, Lira CDG, Justino JMR, Miranda MGO, Saraiva AKM. Direito à saúde da população em situação de rua: reflexões sobre a problemática. Ciência \& Saúde Coletiva 2016; 21(8): 2695-2606.

5. Varanda W, Adorno RCF. Descartáveis urbanos: discutindo a complexidade da população de rua e o desafio para políticas de saúde. Saúde e Sociedade 2004; 13(1): 56-69.

6. Gomes BR, Adorno RCF. Tornar-se "noia": trajetória e sofrimento social nos "usos de crack" no centro de São Paulo. Etnográfica 2011; 15(1): 569-586.

7. Vieira MAC, Bezerra EMR, Rosa CMM. População de rua: quem é, como vive, como é vista. São Paulo: Hucitec; 1994.

8. Mattiello F, Ramos WM. Estudos em psicologia e áreas interdisciplinares sobre a população em situação de rua. Estudos de Psicologia 2018; 23(1): 67-77.

9. Carneiro Junior N, Jesus CH, Crevelim MA. A estratégia saúde da família para a equidade de acesso dirigida à população em situação de rua em grandes centros urbanos. Saúde Soc 2010; 19(3): 709-716.

10. Laurell AC. A saúde-doença como processo social. In: Nunes ED. (Org.). Medicina social: aspectos históricos e teóricos. São Paulo: Global, 1983. p. 133-158. 
11. Souza MT, Silva MD, Carvalho R. Revisão integrativa: o que é e como fazer. Einstein 2010; 8(1): 102106.

12. Minayo MCS. O desafio do conhecimento: pesquisa qualitativa em saúde. São Paulo: Hucitec; 2014.

13. Aguiar MM, Iriart JAB. Significados e práticas de saúde e doença entre a população em situação de rua em Salvador, Bahia, Brasil. Cad Saúde Pública 2012; 28(1): 115-124.

14. Silva CC, Cruz MM, Vargas EP. Práticas de cuidado e população em situação de rua: o caso do Consultório na Rua. Rev Saúde Debate 2015; 39(n.e.): 246-256.

15. Barata RB, Carneiro Junior N, Ribeiro MCSA, et al. Desigualdade social em saúde na população em situação de rua na cidade de São Paulo. Saúde Soc 2015; 24(1): 219-232.

16. Wright NM, Tompkins CN. How can health services effectively meet the health needs of homeless people? The British Journal of General Practice 2006; 56(525): 286-293.

17. White BM, Newman SD. Access to primary care services among the homeless: a synthesis of the literature using the equity of access to medical care framework. Charleston, SC, USA. Journal of Primary Care \& Community Health 2015; 6(2): 77-87.

18. Bordignon JS, Silveira CCS, Delvivo EM, et al. Adultos em situação de rua: acesso aos serviços de saúde e constante busca pela ressocialização. Revisto Contexto \& Saúde 2011; 10(20): 629-634.

19. Brasil. Ministério do Desenvolvimento Social e Combate à Fome. Sumário executivo: pesquisa nacional sobre a população em situação de rua. Brasília; 2008.

20. Hino P, Santos JO, Rosa AS. Pessoas que vivenciam situação de rua sob o olhar da saúde. Revista Brasileira de Enfermagem 2018; 71(supl 1):732-740.

21. Santos CS, Franco ACF, et al. Uma análise sobre o atendimento à população em situação de rua no município de Belém/PA: problematizações acerca do serviço de acolhimento institucional. São Luís do Maranhão, VII Jornada Internacional de Políticas Públicas; 2015.

22. Starfield B. Atenção primária: equilíbrio entre necessidades de saúde, serviços e tecnologia. Brasília: UNESCO/Ministério da Saúde; 2002.

23. Paiva IKS, Lira CDG, Justino JMR, et al. Direito à saúde da população em situação de rua: reflexões sobre a problemática. Ciência \& Saúde Coletiva 2016; 21(8): 2595-2606. 